\title{
Controle químico de Lolium multiflorum: efeito do biótipo e da época de aplicação
}

\author{
Chemical control of Lolium multiflorum: effect of biotype and time of spraying
}

\author{
Liese de Vargas Pereira ${ }^{1,2}$, Leonardo Bianco de Carvalho ${ }^{2,3^{*}}$ e Taísa Dal Magro ${ }^{4}$
}

Recebido em 07/03/2017 / Aceito em 04/05/2017

\section{RESUMO}

Testou-se diferentes herbicidas para controle de dois biótipos de Lolium multiflorum, importante planta daninha de cultivos anuais e perenes, aplicados nos estádios de 3-4 folhas e de pré-florescimento. Independentemente do estádio e do biótipo, a maior eficácia $(>85 \%)$ foi obtida com paraquat e paraquat+diuron. Qualquer um dos herbicidas testados promove controle eficaz $(>85 \%)$ de L. multiflorum quando aplicados em plantas com 3-4 folhas. Quando aplicados no pré-florescimento, além de paraquat e paraquat+diuron, apenas glyphosate e iodosulfuron podem promover controle eficaz $(>85 \%)$, mas com dependência do biótipo. Os herbicidas paraquat e paraquat+diuron são os mais recomendados para o controle de L. multiflorum.

PALAVRAS-CHAVE: herbicidas, azevém, manejo de plantas daninhas.

\footnotetext{
ABSTRACT

Different herbicides were tested to control two biotypes of Lolium multiflorum, an important weed of annual and perennial crops, applied onto 3-4-leaf and pre-flowering stages. Regardless of stage and biotype, the highest efficacy $(>85 \%)$ was obtained with paraquat and paraquat+diuron. Any of the tested herbicides promote effective control $(>85 \%)$ of $L$. multiflorum when applied to 3-4-leaf plants. When applied in pre-flowering, in addition to paraquat and paraquat+diuron, only glyphosate and iodosulfuron can promote effective control $(>85 \%)$, but with dependence the biotype. The herbicides paraquat and paraquat+diuron are the most recommended for the
}

control of L. multiflorum.

KEYWORDS: Herbicides, Italian ryegrass, weed management.

O azevém (Lolium multiflorum) é uma planta daninha de ciclo anual, presente em lavouras de inverno, em pomares e vinhedos da região Sul do Brasil (SCHNEIDER et al. 2015) e no mundo. Casos de azevém resistente a herbicidas foram relatados em diversas partes do mundo, sendo que, no Brasil, há relatos oficias de resistência aos herbicidas glyphosate, iodosulfurom-methyl, clethodim e pyroxsulam, incluindo casos de resistência múltipla (HEAP 2017). Em função disso, a busca por herbicidas alternativos para controle de azevém, resistente ou não, é importante para o manejo adequado e viável, além da prevenção da evolução de populações resistentes desta planta daninha. Ainda, sabe-se que a ação de herbicidas é influenciada pelo estádio da planta daninha no momento da aplicação (CARVALHO 2013), independentemente de ser resistente ou não a herbicidas, assim como a resposta entre diferentes biótipos pode ser distinta. Por isso, o objetivo deste trabalho foi avaliar a eficácia de controle de alguns herbicidas (graminicidas e de ação total) para o controle de dois biótipos azevém, aplicados em dois estádios de crescimento da planta daninha (3-4 folhas e pré-florescimento).

O experimento foi conduzido em casa de vegetação, utilizando sementes de um biótipo de azevém coletado em área de cultivo anual (cereais) e outro, em área de cultivo perene (pomar). As sementes dos dois biótipos foram semeadas em bandejas plásticas e, ao atingirem o estádio de duas folhas, as plantas foram transplantadas para vasos

1 Secretaria Estadual da Agricultura, Pecuária e Irrigação do Rio Grande do Sul, Porto Alegre, RS, Brasil.

2 Universidade do Estado de Santa Catarina, Lages, SC, Brasil.

3 Universidade Estadual Paulista, Dracena, SP, Brasil.

4 Universidade de Caxias do Sul, Vacaria, RS, Brasil.

* Autor para correspondência <lbcarvalho@fcav.unesp.br> 
com capacidade de $3 \mathrm{~L}$, com posterior manutenção de uma planta por vaso.

O delineamento experimental foi inteiramente casualizado com quatro repetições e os tratamentos foram agrupados em três fatores, constituindo um

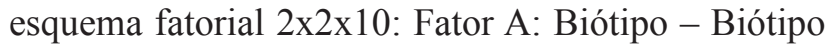
1 (cultivo anual) e Biótipo 2 (cultivo perene); Fator B: Estádio 1 de 3-4 folhas e Estádio 2 de pré-florescimento; Fator C: Herbicida - glyphosate (Roundup WG ${ }^{\circledR}-2,5$ $\left.\mathrm{kg} \mathrm{ha}^{-1}\right)$; tepraloxydim $\left(\right.$ Aramo $^{\circledR}-0,5 \mathrm{~L} \mathrm{ha}^{-1}+5 \mathrm{~mL}$ de Assist $^{\circledR}$ ); iodosulfuron-methyl (Hussar ${ }^{\circledR}-70 \mathrm{~g} \mathrm{ha}^{-1}$ ); paraquat+diuron $\left(\right.$ Gramocil $\left.^{\circledR}-2,0 \mathrm{~L} \mathrm{ha}^{-1}\right)$; paraquat (Gramoxone $^{\circledR}$ - 2,0 L ha-1); clodinafop-propargyl (Topik $^{\circledR}-0,25 \mathrm{~L} \mathrm{ha}^{-1}$ ); fenoxaprop-p-etyl+clethodim $\left(\right.$ Selefen $^{\circledR}-1,0$ L ha $\left.^{-1}\right)$; clethodim $\left(\right.$ Select $^{\circledR}-0,45 \mathrm{~L}$ ha $^{-1}+5 \mathrm{~mL}$ de Lanzar $\left.^{\circledR}\right)$; sethoxydim $\left(\right.$ Poast $^{\circledR}-1,25$ $\mathrm{L} \mathrm{ha}^{-1}$ ) e testemunha (sem aplicação de herbicida). Os herbicidas foram aplicados com pulverizador costal pressurizado a $\mathrm{CO}_{2}$, com pontas de pulverização do tipo leque, calibrado para vazão de $150 \mathrm{~L} \mathrm{ha}^{-1}$ de calda herbicida.

A eficácia de controle foi avaliada aos 7, 14, 21 e 28 dias após o tratamento (DAT), utilizando-se de escala percentual na qual zero (0) e cem (100), correspondem à ausência de injúria e morte das plantas, respectivamente.
Os dados foram submetidos à análise de variância (teste F) e as médias foram comparadas pelo teste de Tukey HSD, para comparação múltipla de médias, a $5 \%$ de probabilidade.

Comparando os biótipos aos 14 DAA, observouse que o Biótipo 1 (73\%) foi controlado de maneira mais eficaz com o uso de herbicidas do que o Biótipo 2 (55\% (Tabela 1). Nesse período, para o Estádio de 3-4 folhas, verificou-se que os herbicidas glyphosate, sethoxydim, clodinafop-propargyl e fenoxaprop-pethyl proporcionaram melhor controle do Biótipo 1; porém, para o Estádio de Pré-florescimento, apenas o herbicida glyphosate proporcionou melhor controle do Biótipo 1 (Tabela 1). Por outro lado, comparando os biótipos aos 28 DAA, observou-se que ambos os biótipos foram controlados com eficácia similar pelo uso de herbicidas (Tabela 2). Nesse período, houve melhor controle do Biótipo 1 apenas no Estádio de Pré-florescimento com os herbicidas glyphosate e fenoxaprop-p-ethyl (Tabela 2). Portanto a diferença inicial de controle com glyphosate se manteve aos 28 DAA, enquanto para os demais herbicidas a diferença não permaneceu. Além disso, a semelhança de controle com o fenoxaprop-p-ethyl em 14 DAA não foi mantida em 28 DAA.

Tabela 1. Nível de controle (relativo à testemunha) de dois biótipos de Lolium multiflorum em dois estádios de crescimento, aos 14 dias após aplicação de herbicidas de diferentes mecanismos de ação.

Table 1. Control level (relative to check) of two biotypes of Lolium multiflorum in two growth stages, at 14 days after application of herbicides with different modes of action.

\begin{tabular}{lcccc}
\hline \multirow{2}{*}{ Tratamento } & \multicolumn{2}{c}{ Biótipo 1 } & \multicolumn{2}{c}{ Biótipo 2 } \\
\cline { 2 - 5 } & $3-4$ Folhas & Pré-florescimento & $3-4$ Folhas & Pré-florescimento \\
\hline Glyphosate & $94 \mathrm{ab}$ & $79 \mathrm{~b}$ & $18 \mathrm{e}$ & $16 \mathrm{e}$ \\
Clethodim & $74 \mathrm{bc}$ & $34 \mathrm{de}$ & $54 \mathrm{~cd}$ & $26 \mathrm{de}$ \\
Sethoxydim & $98 \mathrm{a}$ & $31 \mathrm{de}$ & $60 \mathrm{c}$ & $29 \mathrm{de}$ \\
Tepraloxydim & $99 \mathrm{a}$ & $64 \mathrm{bc}$ & $96 \mathrm{ab}$ & $75 \mathrm{bc}$ \\
Clodinafop-propargyl & $81 \mathrm{ab}$ & $33 \mathrm{de}$ & $39 \mathrm{~d}$ & $26 \mathrm{de}$ \\
Fenoxaprop-p-ethyl & $89 \mathrm{ab}$ & $21 \mathrm{de}$ & $50 \mathrm{~cd}$ & $33 \mathrm{de}$ \\
Iodosulfurom-methyl & $77 \mathrm{bc}$ & $33 \mathrm{de}$ & $50 \mathrm{~cd}$ & $33 \mathrm{de}$ \\
Paraquat & $99 \mathrm{a}$ & $98 \mathrm{a}$ & $99 \mathrm{a}$ & $93 \mathrm{ab}$ \\
Paraquat+Diuron & $99 \mathrm{a}$ & $98 \mathrm{a}$ & $99 \mathrm{a}$ & $97 \mathrm{ab}$ \\
\hline Biótipo 1 vs Biótipo 2 & \multicolumn{5}{c}{$55 \mathrm{~b}$} \\
\hline Estádio 1 vs Estádio 2 & $90 \mathrm{a}$ & $73 \mathrm{a}$ & $63 \mathrm{~b}$ & $48 \mathrm{~b}$ \\
\hline Médias seguidas pela mesma letra não diferem entre si pelo teste de comparações múltiplas de Tukey HSD, a 5\% de \\
probabilidade.
\end{tabular}


Tabela 2. Notas de controle (relativo à testemunha) de dois biótipos de Lolium multiflorum em dois estádios de crescimento, aos 28 dias após aplicação de herbicidas de diferentes mecanismos de ação.

Table 2. Control level (relative to check) of two biotypes of Lolium multiflorum in two growth stages, at 28 days after application of herbicides with different modes of action.

\begin{tabular}{lcccc}
\hline \multirow{2}{*}{ Tratamento } & \multicolumn{3}{c}{ Biótipo 1 } & \multicolumn{2}{c}{ Biótipo 2 } \\
\cline { 2 - 5 } & 3-4 Folhas & Pré-florescimento & $3-4$ Folhas & Pré-florescimento \\
\hline Glyphosate & $99 \mathrm{a}$ & $99 \mathrm{a}$ & $99 \mathrm{a}$ & $20 \mathrm{e}$ \\
Clethodim & $99 \mathrm{a}$ & $63 \mathrm{c}$ & $89 \mathrm{ab}$ & $63 \mathrm{c}$ \\
Sethoxydim & $99 \mathrm{a}$ & $63 \mathrm{c}$ & $99 \mathrm{a}$ & $63 \mathrm{c}$ \\
Tepraloxydim & $99 \mathrm{a}$ & $61 \mathrm{c}$ & $99 \mathrm{a}$ & $64 \mathrm{c}$ \\
Clodinafop-propargyl & $99 \mathrm{a}$ & $40 \mathrm{~d}$ & $89 \mathrm{ab}$ & $40 \mathrm{~d}$ \\
Fenoxaprop-p-ethyl & $99 \mathrm{a}$ & $60 \mathrm{c}$ & $99 \mathrm{a}$ & $35 \mathrm{~d}$ \\
Iodosulfurom-methyl & $98 \mathrm{a}$ & $86 \mathrm{ab}$ & $96 \mathrm{a}$ & $80 \mathrm{~b}$ \\
Paraquat & $99 \mathrm{a}$ & $99 \mathrm{a}$ & $99 \mathrm{a}$ & $99 \mathrm{a}$ \\
Paraquat+Diuron & $99 \mathrm{a}$ & $99 \mathrm{a}$ & $99 \mathrm{a}$ & $99 \mathrm{a}$ \\
\hline Biótipo 1 vs Biótipo 2 & \multicolumn{4}{c}{$80 \mathrm{a}$} \\
\hline Estádio 1 vs Estádio 2 & $99 \mathrm{a}$ & $74 \mathrm{~b}$ & $96 \mathrm{a}$ \\
\hline Médias seguidas pela mesma letra não diferem entre si pelo teste de comparações múltiplas de Tukey HSD, a 5\% de \\
probabilidade.
\end{tabular}

Comparando os estádios aos 14 DAA, observouse que apenas para o Biótipo 1 a aplicação de herbicidas no Estádio de 3-4 folhas foi mais eficaz (90\%) que no Estádio de Pré-florescimento (55\%) (Tabela 1). Nesse período, para o Biótipo 1, houve melhor controle no Estádio de 3-4 folhas para os herbicidas clethodim, sethoxydim, tepraloxydim, clodinafop-propargyl, fenoxaprop-p-ethyl e iodosulfuron-methyl, enquanto para o Biótipo 2 essa diferença foi observada apenas com sethoxydim (Tabela 1). Por outro lado, aos 28 DAA, as diferenças intensificaram-se principalmente no Biótipo 2, mas observou-se diferença entre estádios tanto para o Biótipo $1(99 \%$ e $74 \%)$ quanto para o Biótipo 2 (96\% e 63\%), respectivamente para os estádios de 3-4- folhas e Pré-florescimento (Tabela 2). Para o Biótipo 1, a diferença não se manteve apenas para iodosulfurom-methyl, enquanto para o Biótipo 2, além de sethoxydim, as diferenças também ocorreram com glyphosate, clethodim, tepraloxydim, clodinafoppropargyl, fenoxaprop-p-ethyl e iodosulfuron-methyl (Tabela 2).

Complementa-se que, independentemente do estádio e do biótipo, a maior eficácia $(>85 \%)$ foi obtida com paraquat e paraquat+diuron, sendo estes os herbicidas mais recomendados para o controle de L. multiflorum. Inclui-se que qualquer um dos herbicidas testados promove controle eficaz (>85\%) de L. multiflorum quando aplicados no Estádio de 3-4- folhas. Ainda, se aplicados no Estádio de Préflorescimento, além de paraquat e paraquat+diuron, apenas glyphosate e iodosulfuron podem promover controle eficaz $(>85 \%)$, mas com dependência do biótipo.

As doses usadas neste experimento estão de acordo com a recomendação dos fabricantes (AGROFIT 2017). Porém, alguns autores verificaram que a eficácia controle de L. multiflorum é dependente da dose do herbicida (ROMAN et al. 2004, VARGAS et al. 2004, SCHNEIDER et al. 2015), do estádio de aplicação (SANTOS et al. 2015) e também do genótipo (CARGNIN et al. 2006), além obviamente do herbicida usado (ROMAN et al. 2004, VARGAS et al. 2004, CARGNIN et al. 2006, SCHNEIDER et al. 2015). Além disso, foi constatada a alta eficácia de controle de L. multiflorum com o uso de paraquat (ROMAN et al. 2004, VARGAS et al. 2004, SCHNEIDER et al. 2015). O paraquat é um herbicida inibidor de fotossistema I (CARVALHO 2013), diferentemente dos demais herbicidas testados, sendo, portanto, uma alternativa interessante de controle e prevenção da evolução de resistência. Além disso, a mistura do paraquat com o diuron (herbicida inibidor 
do fotossistema II - CARVALHO 2013) torna ainda mais segura a aplicação, uma vez que se tem outro mecanismo de ação envolvido.

Para controlar L. multiflorum em áreas sem cultivo ou na entressafra de áreas cultivadas é possível conseguir controle eficaz, uma vez que paraquat e paraquat+diuron (herbicidas não seletivos) não acarretariam problemas para plantas de interesse. Porém, em áreas cultivadas, alguns problemas poderiam ocorrer. Primeiramente, se a aplicação ocorrer em áreas de cultivos anuais, esses dois herbicidas não seriam seletivos e seu uso estaria restrito a momentos em que as culturas não estivessem presentes. Em cultivos perenes, como pomares, a aplicação tem que ser em jato dirigido e protegido, para evitar contato dos herbicidas com a planta de interesse. Porém, no caso de aplicações em pós-emergência das culturas, por exemplo, as opções de controle eficaz são reduzidas. No caso de cereais de inverno, em que L. multiflorum comumente ocorre, o iodosulfuron-methyl (seletivo para trigo e aveia) seria a única opção com eficácia não tão alta e com dependência do estádio e do biótipo. Além disso, no caso de controle de L. multiflorum no início do ciclo de culturas não gramíneas, como a soja, haveria opções eficazes de controle (graminicidas), mas apenas quando a planta daninha estivesse em estádios iniciais de crescimento.

Paraquat e paraquat+diuron são os herbicidas mais eficazes para controle de L. multiflorum, independentemente do biótipo e do estádio de crescimento.

\section{REFERENCES}

AGROFIT. 2017. Sistema de agrotóxicos fitossanitários. Disponível em: <http://extranet.agricultura.gov.br/agrofit_ cons/principal_agrofit_cons $>$. Acesso em: 03 jan. 2017.

CARGNIN A et al. 2006. Uso de herbicidas seletivos na produção de aveia branca. Revista Ceres 53:139-143.

CARVALHO LB. 2013. Herbicidas. Lages: Ed. Autor. 62p. HEAP I. 2017. International survey of herbicide resistant weeds. Disponível em: $<\mathrm{http}: / /$ weedscience.com/>. Acesso em: 03 jan. 2017.

ROMAN ES et al. 2004. Resistência de azevém (Lolium multiflorum) ao herbicida glyphosate. Planta Daninha 22: 301-306.

SANTOS JC et al. 2015. Effect of application time of sulfonylurea herbicides to control annual ryegrass in wheat crops. Revista Brasileira de Herbicidas 14: 117-127.

SCHNEIDER T et al. 2015. Alternative control of ryegrass biotypes resistants to clethodim. Revista Brasileira de
Herbicidas 14: 243-247.

VARGAS L et al. 2004. Identificação de biótipos de azevém (Lolium multiflorum) resistentes ao herbicida glyphosate em pomares de maça. Planta Daninha 22: 617-622. 